\title{
DYNAMIC MODELLING OF HEATING COSTS OF AN AIR CONDITIONER IN THREE DIFFERENT CLIMATE REGIONS IN TURKEY
}

\author{
Mustafa MUTLU \\ Uludag University, Vocational School of Yenisehir Ibrahim Orhan, Air Conditioning and \\ Refrigeration Tech. Program, 16900 Yenisehir, Bursa, Turkey \\ E-mail: mustafamutlu@uludag.edu.tr
}

Received: 2 February 2018; Accepted: 29 April 2018

The applications of AC unit for heating purposes increase with the improvements in air conditioners' (AC) automation, performance, and production lines. Besides the developments in technology, heating applications of AC units can be a sustainable and effective solution with the aim of reducing $\mathrm{CO} 2$ emissions. In this study, heating costs of a simple dwelling were calculated. Three cities that represent three different climates in Turkey were chosen. Unlike steady-state equations to determine heating loads, transient heat conduction in wall and window components were solved by applying the finite difference method. Temperature deviation in wall and window materials among to thickness direction was calculated. Thus more accurate heating loads were obtained. In order to get realistic results, actual energy prices were used in cost calculations. Heating costs of AC unit that electricity is the only expense were compared with a natural gas burner. It is found that the AC unit is more economical than a gas burner in warm climate region because COP values of $A C$ unit are the parameter that determines the electricity cost. COP in warm climate locations is much higher than that of cold climate region. In regards to heating costs, outside temperature and wind speed characteristics of a place where a building will be constructed should be well-known in order to choose the proper heating system.

Key words: Energy consumption, Heating costs, Transient heat conduction, Air source heat pumps.

\section{Introduction}

Household $\mathrm{CO}_{2}$ emissions are not negligible for a sustainable environment, considering the $25 \%$ of total energy consumption are used in residential buildings and $40 \%$ of this energy is consumed for heating applications [1]. Thus, heating systems used in houses are responsible for a substantial amount of $\mathrm{CO}_{2}$ emissions. Despite fossil fuels (coal, natural gas, fuel oil etc.) are widely used for heating purposes today, the contribution of renewable energy sources (such as wind and solar energy) in residential buildings increases day by day. One of the effective way to use renewable energy sources for heating application is an air conditioner known as heat pump. When the required energy of natural gas burner, fuel oil burner, electrical heating and a heat pump system is evaluated for a 100 units heating demand, it is seen that, the primary energy consumption of these systems becomes 119, 121, 294 and 101 units energy respectively [2]. 
$\mathrm{AC}$ units can be high-priced application due to electricity prices even it has advantages of low $\mathrm{CO}_{2}$ emission and primary energy sources consumption. Heating costs of $\mathrm{AC}$ units should be compete with other fuel types in order to be widespread at houses. One of the important studies on this topic was done by Kelly and Cockroft [3], in which a mathematical model and experimental data collected from a domestic house, located in England, were used. They calculated that the $\mathrm{CO}_{2}$ emission is $12 \%$ lower while the heating cost of air source heat pump (ASHP) is about $10 \%$ higher than that of natural gas. A similar study was done by Serpen and Palabiyık [4] for Turkey and the same results were obtained. It is also mentioned that this situation has a potential to change regarding to rise in electricity and natural gas prices. The heating costs of natural gas were compared with a heat pump application in another study that related to Turkey. It is concluded that, heat pump applications were more economical for condenser temperature below $100{ }^{\circ} \mathrm{C}$ while natural gas ones were more economical above $100{ }^{\circ} \mathrm{C}$ [5]. It is stated that, heat pump usage becomes more economical due to improvements in heat pump technology and increases in energy prices [6]. According to a study where TRANSYS software was used, it is found that, heat pump is more economical for heating and $\mathrm{CO}_{2}$ emissions and it can be reduced up to $36 \%$ [7]. Six different heating systems were compared by Pineau et al. [8] using TRANSYS software for low energy buildings and it was found that the most economical heating systems were micro combined heat and power (MCHP) and absorption heat pumps. However, it was determined that the most suitable system was air to water heat pump because of the lack of small size MCHP and absorption heat pump systems. It was seen that, air source heat pumps perform well in case of low heating degree-days (HDD). Zhang et al. [9] compared different heating systems using a mathematical model and they calculated the low temperature heat pump as the most economical system. TRANSYS model of a two-stage air source heat pump was verified by Safa et al. using field data [10]. It was observed that, when outside temperature was between $-19{ }^{\circ} \mathrm{C}$ and $9{ }^{\circ} \mathrm{C}$, the coefficient of performance (COP) for heating varied between 1.79 and 5 .

Energy-focused renovation of existing buildings came into question as a result of energy consumption and $\mathrm{CO}_{2}$ emission targets of Europe Union and other developed countries. Replacing existing heating systems with heat pumps in these buildings contributes to achieving environmental targets. One of the studies using a net present value method and profitability index showed that, air source heat pumps had the lowest energy consumption and energy intensity [11]. Examining the air to water heat pump retrofit in Canada housing stock, Asaee et al. determined that energy consumption and greenhouse gas emissions could be reduced by $36 \%$ and $23 \%$ respectively [12]. On the other hand, Gram-Hanssen et al. found that using heat pumps instead of electricity in summerhouses located in Denmark had no effect on energy consumption. However, it was observed that thermal comfort was improved despite the energy consumption remained stable because of user behaviour [13].

In the literature, the expressions used for determining heating loads as well as economical calculations of heat pumps, are valid under steady-state condition. Steady-state expression can cause undesired solutions when outside and inside temperatures vary with time rapidly. Meteorological data is the key input of mathematical models and calculations to determine performance of heat pumps. Sudden changes cannot be examined as the resolution of meteorological data increases, because the effect of variations in wind speed and temperatures decreases in mean data. Thus the effect of variation in outdoor condition (temperature and wind speeds) influences the indoor temperature significantly in case of calculations when low-resolution meteorological data is used. For example, in steady-state calculations heat transfer rises notably as the heat transfer coefficient increases due to high outdoor wind 
speed and it causes a substantial decrease or increase in indoor temperature. In this kind of calculations, results incompatible with reality may be obtained since heat storage capacity of the wall materials and transient heat transfer are ignored.

In this study, heating costs of an air conditioner and natural gas burner usage in a building were calculated. It was assumed that the building was located in three different cities, which represent three different climate regions of Turkey. The calculations were done by using last four years' $(2014-2017)$ meteorological data of these cities. Heating costs of the two systems were compared and it was found that AC system was more economical in cities with low HDD.

\section{Material and Method}

In this study, it was assumed that the heated area was located in three different cities that have different climate conditions in Turkey (Fig.1). These cities are Antalya (36 $\left.53^{\circ} 14.6^{\prime \prime} \mathrm{N} \mathrm{30} 42^{\prime} 27.1^{\prime \prime} \mathrm{E}\right)$, Bursa (40¹0'58.1"N 2904'01.7"E) and Erzurum (3954'20.5"N 41 $\left.{ }^{\circ} 16^{\prime} 06.8^{\prime \prime} \mathrm{E}\right)$.

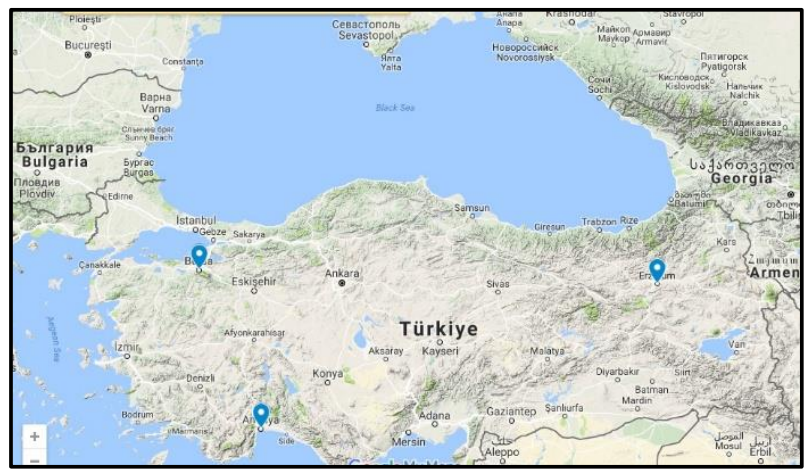

Fig.1. Location of cities

In order to obtain comparable results, a building with dimensions $10 \mathrm{~m} \times 10 \mathrm{~m} \times 3 \mathrm{~m}$ was considered and these metrics were used when needed. Meteorological data of last four years contain outside temperature and wind speed between the dates October 15 and March 15. Minimum, maximum and average temperature data of heating seasons were given in Tab.1.

Table 1. Minimum, maximum and average air temperatures in chosen cities

\begin{tabular}{|c|l|c|c|c|}
\hline \multirow{5}{*}{ City } & $\begin{array}{l}\text { Heating } \\
\text { Season }\end{array}$ & $\begin{array}{l}\text { Minimum } \\
\text { Temperature } \\
{\left[{ }^{\circ} \mathrm{C}\right]}\end{array}$ & $\begin{array}{l}\text { Maximum } \\
\text { Temperature } \\
{\left[{ }^{\circ} \mathrm{C}\right]}\end{array}$ & $\begin{array}{l}\text { Average } \\
\text { Temperature } \\
{\left[{ }^{\circ} \mathrm{C}\right]}\end{array}$ \\
\hline \multirow{4}{*}{ Antalya } & $2014-2015$ & -0.4 & 28.4 & 14.2 \\
\cline { 2 - 5 } & $2015-2016$ & 1.1 & 27.8 & 15 \\
\cline { 2 - 5 } & $2016-2017$ & 2.5 & 31 & 14.2 \\
\hline \multirow{4}{*}{ Bursa } & $2014-2015$ & -9.4 & 28.3 & 9 \\
\cline { 2 - 5 } & $2015-2016$ & -14 & 26.4 & 9.4 \\
\cline { 2 - 5 } & $2016-2017$ & -6.3 & 28.5 & 7.4 \\
\hline \multirow{3}{*}{ Erzurum } & $2014-2015$ & -19.7 & 15.9 & -0.9 \\
\cline { 2 - 5 } & $2015-2016$ & -26.3 & 19.1 & -1.3 \\
\cline { 2 - 5 } & $2016-2017$ & -27.6 & 15.5 & -4.1 \\
\hline
\end{tabular}


Indoor set temperature $\left(T_{\text {set }}\right)$ was adjusted to three different values $\left(19^{\circ} \mathrm{C}, 20^{\circ} \mathrm{C}\right.$ and $\left.21^{\circ} \mathrm{C}\right)$ and calculations are repeated for each set of temperature. Finite difference method was used by applying the first law of thermodynamics [14] in order to determine heat transfer rate from surfaces in the developed model. Calculations were done by $\mathrm{C}++$ programming language and the flow chart of the program was given in Fig.2. Time step $(\Delta t)$ was taken $0.05 \mathrm{~s}$ in the model. It is obvious that selected time step will give precise results when considering that, 1-minute time step was chosen in a similar research [10], where TRANSYS software was used.

Wind speed $\left(V_{w}\right)$ and outdoor temperature $\left(T_{o}\right)$ taken from meteorological data was included in the program from a separate file. Temperature data were in hourly averages, while wind speed data were in daily averages and this situation was taken into account in programming.

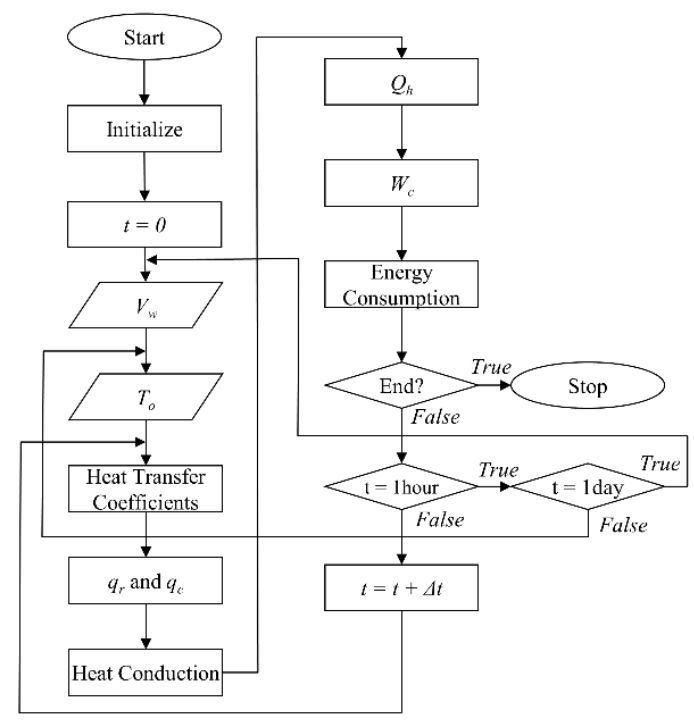

Fig.2. Flowchart of the program

\subsection{Heat Transfer Calculations}

Heat transfer rates were determined by calculating net energy transfer from surfaces for each time step instead of heat transfer per unit time, due to transient nature of the problem. Then the heat transfer, being between hot indoor air and cold inner wall surfaces can have been calculated by Newtons' cooling law (Eq. (1)).

$$
q_{i}=h_{i}\left(T_{i}-T_{s i}\right) \Delta t
$$

In this equation, $T_{i}$ and $T_{s i}$ represent the indoor air temperature and indoor wall or window surface temperature respectively. Heat transfer coefficient $\left(h_{i}\right)$ between surfaces and indoor air is assumed constant, $7.69 \mathrm{~W} / \mathrm{m}^{2} \mathrm{~K}$ according to "Thermal Insulations Requirements for Buildings" of Turkish Standards [15]. Convection and radiation heat transfer rates were calculated separately, then their totals were taken in order to obtain heat transfer between outdoor air and outer surfaces (Eq. (2)).

$$
q_{o}=q_{c o n}+q_{r}
$$


Heat convection through outdoor environment $\left(q_{c o n}\right)$ was calculated by Newton's cooling law (Eq.3) similar to Eq.(1). Outer wall surface temperature $\left(T_{s o}\right)$ and heat transfer coefficient between outdoor air and surfaces in Eq.(3) were calculated depending on outdoor conditions (air temperature $T_{o}$ and wind speed $V_{w}$ ) for each time step.

$$
q_{c o n}=h_{o}\left(T_{s o}-T_{o}\right)
$$

Heat transfer coefficient $\left(h_{o}\right)$ between building surfaces and outdoor air was calculated by expressions $($ Eqs.4, 5) form the literature instead of standards [16].

$$
\begin{gathered}
N u=\left(0.0037 \operatorname{Re}^{0.8}-871\right) \operatorname{Pr}^{0.3} \\
h_{o}=\frac{N u k_{a}}{L}
\end{gathered}
$$

Heat conduction of air $(k a)$ and characteristic length $(L)$ were used and thermal properties of air were assumed constant when heat transfer coefficient was calculating (Tab.2).

Table 2. Thermal properties of air

\begin{tabular}{|l|l|}
\hline Density & $1.1614 \mathrm{~kg} / \mathrm{m}^{3}$ \\
\hline Heat Capacity & $1007 \mathrm{~J} / \mathrm{kgK}$ \\
\hline Conduction Coefficient & $0.0263 \mathrm{~W} / \mathrm{mK}$ \\
\hline Prandtl Number & 0.707 \\
\hline
\end{tabular}

Radiation heat transfer rates from surfaces were calculated by Eq. (6) where $\sigma$ was StefanBoltzman constant $\left(5.67 \times 10-8 \mathrm{~W} / \mathrm{m}^{2} \mathrm{~K}^{4}\right)$ and emissivity of surfaces were assumed to be 0.9 .

$$
q_{r}=\sigma \varepsilon\left(T_{s o}^{4}-T_{o}^{4}\right)
$$

\subsection{Compressor power and COP calculations}

In this study, a compressor model, suggested by Mutlu and Çalışkan [6], was used in order to determine the compressor power and coefficient of performance of the system related to compressor power. In this model, after calculating heat loss, a PID algorithm using this value determines heating capacity. COP of heat pump can be found by a function proposed by Eq. (7).

$$
C O P=a+b Q_{i n}+c T_{o}+d Q_{h}^{2}+e T_{o}^{2}
$$

In this equation, $Q_{h}$ indicates heating capacity of the heat pump in Watt and parameters, $a, b, c, d$ and $e$, depending on $T_{i}$ can be calculated by Eq. (8).

$$
\begin{aligned}
& a=0.1757 T_{i}-0.8919 \\
& b=-0.0142 T_{i}+0.3659
\end{aligned}
$$




$$
\begin{gathered}
c=0.0024 T_{i}+0.0563 \\
d=0.00002812 T_{i}^{2}-0.00087036 T_{i}+0.00432 \\
e=-0.00005392 T_{i}+0.00455332
\end{gathered}
$$

After $Q_{h}$, the heat load of the heat pump, and the COP are determined, the instantaneous power of the compressor $\left(W_{c}\right)$ can be calculated by Eq. (9). In each time step $(\Delta t)$, the required energy $(E)$ for heating demand can be found by using $W_{c}$ and time step (Eq. (10)). The total required energy $\left(E_{t}\right)$ for a heating season can be calculated by the sum of energy components needed in each time step.

$$
\begin{gathered}
W_{c}=\frac{Q_{h}}{C O P} \\
E=W_{c} \Delta t
\end{gathered}
$$

\subsection{Heat conduction in wall and window materials}

Heat loss calculations, where wall and window materials' temperature were calculated by finite difference method were done according to outdoor temperature and wind speed in each time step in regard to transient heat conduction. Wall and window materials were divided into 10 equal layer and each layer temperature was calculated by assuming that heat conduction was in one direction. Thermal properties of wall and window materials were given in Tab. 3. According to suggested total heat transfer values in Turkish standards, thermal insulation thickness was selected between $0.04 \mathrm{~m}$ and $0.1 \mathrm{~m}$ in regard to city location. The thickness of the insulation layer in Erzurum, which was the coldest among selected cities, was $0.1 \mathrm{~m}$, while it was $0.04 \mathrm{~m}$ in Antalya. Detailed information about finite difference method and its application can be found in literature [16].

Table 3. Thermal properties of wall and window materials

\begin{tabular}{|l|c|c|c|c|}
\hline Material & $\begin{array}{c}\text { Thickness } \\
{[\mathrm{m}]}\end{array}$ & $\begin{array}{c}\text { Density } \\
{[\mathrm{kgm}-3]}\end{array}$ & $\begin{array}{c}\text { Conduction Coefficient } \\
{[\mathrm{Wm}-1 \mathrm{~K}-1]}\end{array}$ & $\begin{array}{c}\text { Heat Capacity } \\
{[\mathrm{Jkg}-1 \mathrm{~K}-1]}\end{array}$ \\
\hline \multicolumn{5}{|c|}{ Wall } \\
\hline Plaster & 0.03 & 1800 & 0.7 & 880 \\
\hline Brick & 0.18 & 1600 & 0.5 & 840 \\
\hline Insulation & $0.04-0.1$ & 200 & 0.04 & 670 \\
\hline Plaster & 0.03 & 1800 & 0.7 & 880 \\
\hline \multicolumn{5}{|c|}{ Window } \\
\hline Glass & 0.002 & 2720 & 0.7 & 880 \\
\hline Still air & 0.02 & 1.1614 & 0.0263 & 1007 \\
\hline Glass & 0.002 & 2720 & 0.7 & 880 \\
\hline
\end{tabular}

Temperature distribution and temperature variations with time of wall and window materials can be determined correctly by this method. More accurate results could be obtained by determining inner and outer surface temperatures of walls and windows, which are very crucial for heat loss and gains calculations. Furthermore, heat capacity specifications of wall and window materials are considered, thus more realistic results could be found for indoor air temperature. 


\subsection{Energy prices and cost calculations}

In this study, economical comparison of a heat pump and a gas burner used for heating applications was made. Influenced by energy prices, heating costs are increasing year by year. However, when energy prices in last three heating seasons in Turkey are examined, a decline in unit energy price of natural gas could be seen while electric prices are increasing (Fig.3).

Total energy consumption of the building, for both AC and natural gas was separately calculated by the method described in this section. The heating cost of AC comprises only the electricity consumption, while lower heating value and combustion efficiency of natural gas need to be considered in natural gas burner. In this study, the lower heating value of natural gas and the combustion efficiency were assumed $34525 \mathrm{~kJ}$ and 0.92 respectively.

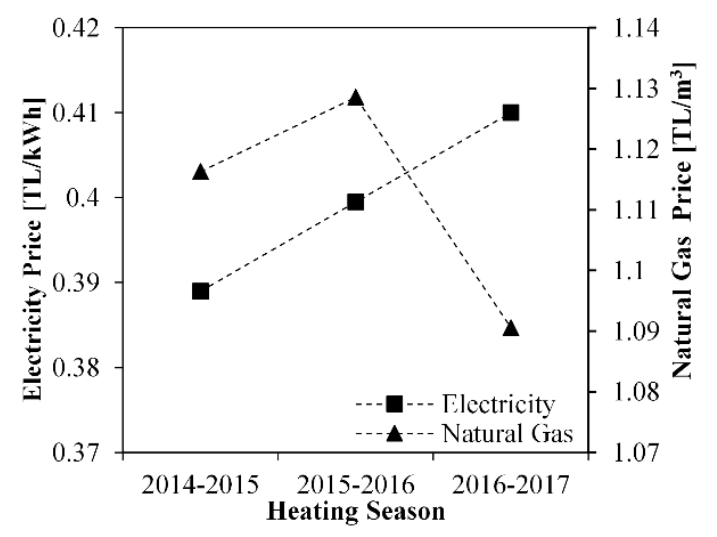

Fig.3. Variation of energy prices by heating season

\section{Results}

Heating cost of a simple residential building assumed to be located in three cities with different climate conditions were examined by a dynamic model using real meteorological data. As it is expected, the heating cost in cities with colder climate is higher than in the other cities. On the other hand, when AC heating cost are examined, it is concluded that heating cost variation with various climate conditions are quite different from a natural gas burner heating cost.

\subsection{Heating cost and COP}

It is seen that, annual heating cost are altered not only by energy prices and weather conditions but also by preferred heating system.

It is seen that in Antalya and Bursa the AC unit is more economical than in Erzurum (Fig.4). More energy is required to meet the same energy demand of the building, because COP decreases in low outdoor temperature (Fig.5a). Heating cost could be saved up to 55\% in Antalya and 25\% in Bursa depending on indoor air temperature and weather by preferring the AC instead of natural gas burner. However, AC unit usage in cold regions like Erzurum may increase the heating cost by up to $36 \%$. Despite AC unit usage has higher heating cost in Erzurum, it can be seen that AC consumes less energy than natural gas burner in all three cities such that $12150 \mathrm{kWh}$ energy required in case of natural gas usage while $4558 \mathrm{kWh}$ energy required in $\mathrm{AC}$ unit. The energy consumption of a heat pump is close to 
$5325 \mathrm{kWh}$, which is obtained by Safa et al [10] in Toronto city and the difference can be explained by transient solution approach, meteorological data and wall materials.

Outdoor air temperature has a significant effect on COP, where it is emphasized in the literature that COP changes linearly with the outdoor temperature [3, 10 17]. Kelly and Cockroft [3] determined that COP was between 2 and 2.5 when outdoor air temperature was between $0{ }^{\circ} \mathrm{C}$ and $-5{ }^{\circ} \mathrm{C}$ in their measurement results and COP reached to 3 while $T_{o}$ is $15{ }^{\circ} \mathrm{C}$. In this study, it seen that, COP values increase rapidly with the increase of outdoor temperature and when $T_{o}$ is equal to $15{ }^{\circ} \mathrm{C}$ average COP becomes 5 . The difference could be explained by operating condition performance of HP that used in mentioned study. On the other hand, when $T_{o}$ is $10{ }^{\circ} \mathrm{C} \mathrm{COP}$ reaches to 5 in experimental data measured by Safa et al [10].
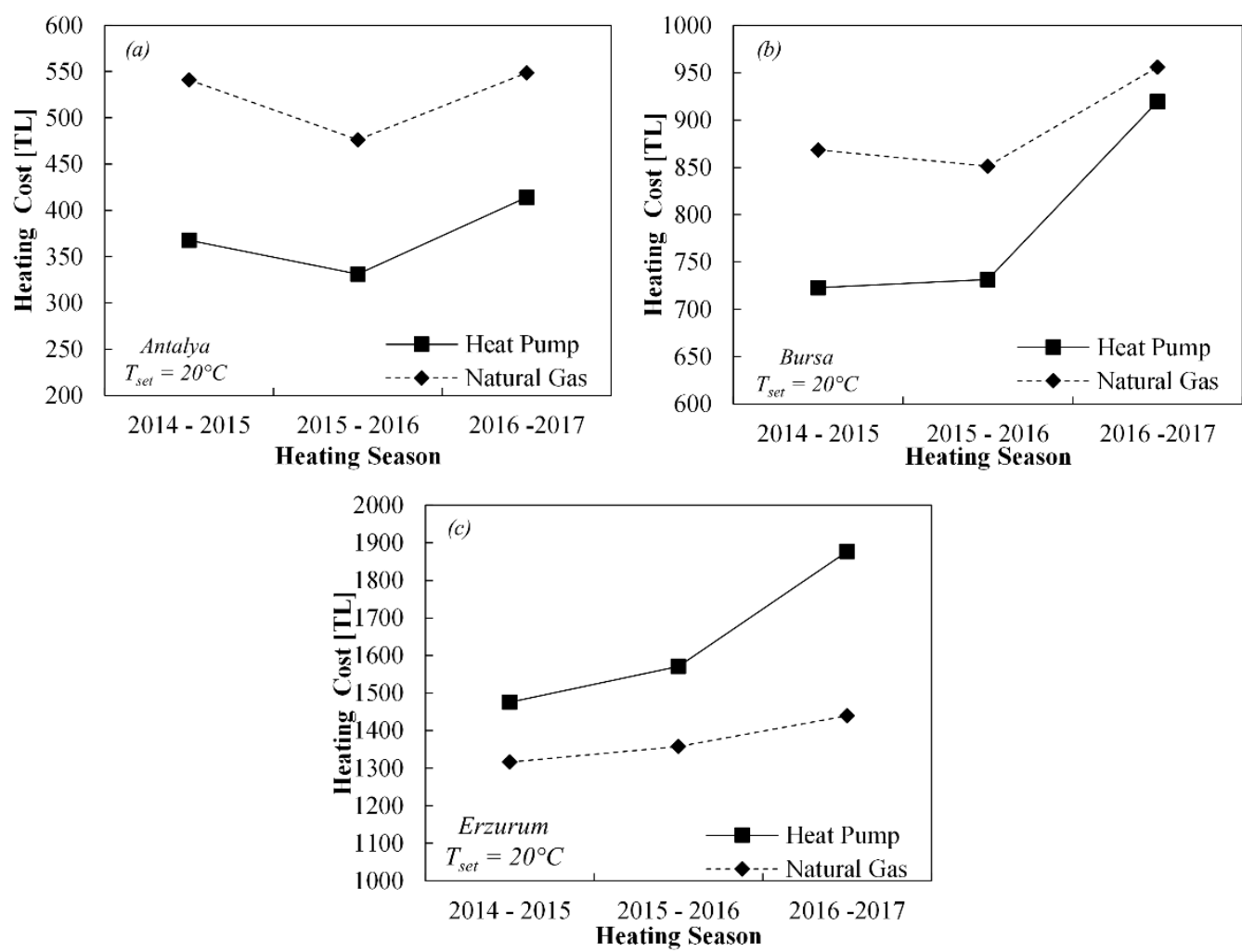

Fig.4. Comparison of heating costs in (a) Antalya, (b) Bursa and (c) Erzurum

The calculated mean COP values for the chosen cities are given in Fig.5b. It can be seen that not only the region has a great effect on AC performance, but also weather conditions. Moreover, different heating season may influence the performance of AC slightly. Fluctuations between heating seasons for a city emphasize that, AC performance may vary slightly from year to year, as well as it is revealed that, long term weather conditions should be considered before huge investments. 

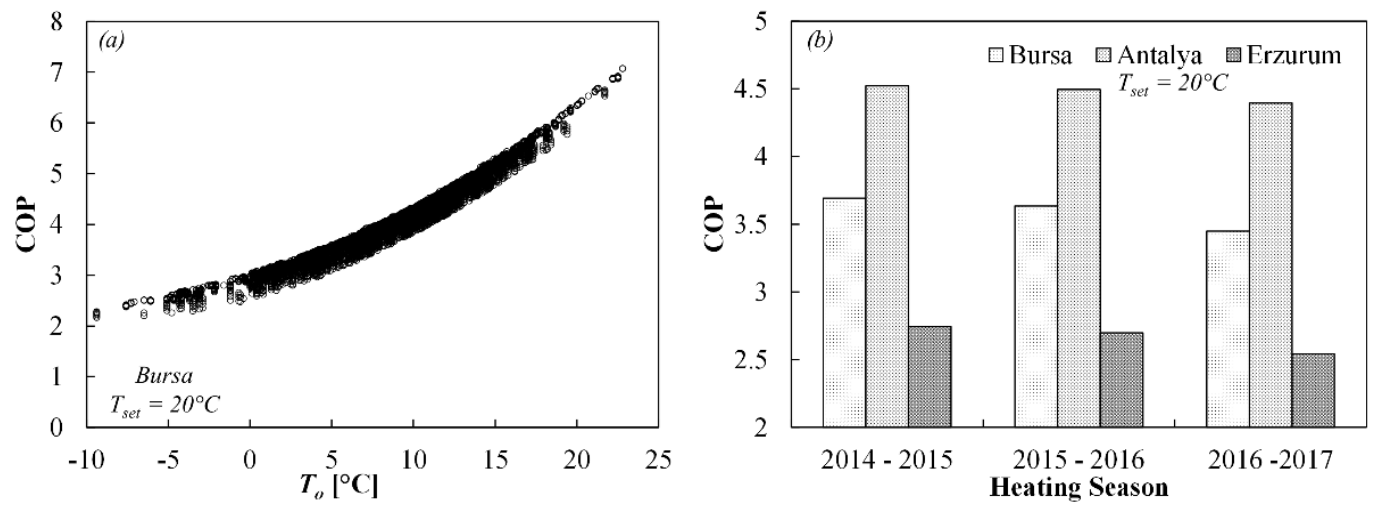

Fig.5. Calculated COP (a) variation with outdoor air temperature and (b) average values in different cities

Days, when the lowest temperatures were experienced, were picked out of results in order to investigate wall surface temperatures. Fig.6a shows that inner wall surface temperature $\left(T_{s i}\right)$ changes in parallel with indoor air temperature $\left(T_{i}\right)$. The similarity of $T_{s i}$ and $T_{o}$ variation was reported by a study that used field measurement, made by Elsawar et al [11]. It should also be noted that $T_{i}$ changes regarding to $T_{o}$. But, temperature difference between indoor air and wall indoor surfaces $\left(T_{i}-T_{s i}\right)$ that measured by Elsawar et al. [11] is higher than that of obtained results from present study because of insulation layer. Elsawar et al. [11] adjusted the indoor air set temperature $\left(T_{\text {set }}\right)$ to $25^{\circ}$, while $T_{\text {set }}$ was $20^{\circ} \mathrm{C}$ in the present calculations. In this study, the difference between $T_{i}$ and $T_{s i}$ remained under $4{ }^{\circ} \mathrm{C}$ even in the coldest day, while $T_{s i}$ variation was below $1{ }^{\circ} \mathrm{C}$. When cities, whose weather conditions are quite different are evaluated, it is seen that indoor wall temperatures show a similar tendency due to insulation.

Outer wall surface temperature $\left(T_{s o}\right)$ is considerably influenced by outdoor air temperature (Fig.6b) and in some cases, $T_{s o}$ may be equal to $T_{o}$, while the change in $T_{s i}$ is limited to $1{ }^{\circ} \mathrm{C}$ even if the building is located in various locations whose weather conditions are quite different. When temperature difference between outer wall surface and outdoor air temperature $\left(T_{s o}-T_{s}\right)$ is examined, it may be concluded that the difference is higher in cold climate regions. High temperature difference $\left(T_{s o}-T_{s}\right)$ increases the heating energy consumption thus the heating cost rises. This temperature difference may be reduced by increasing insulation thickness so that AC applications become economically feasible to operate in cold regions.
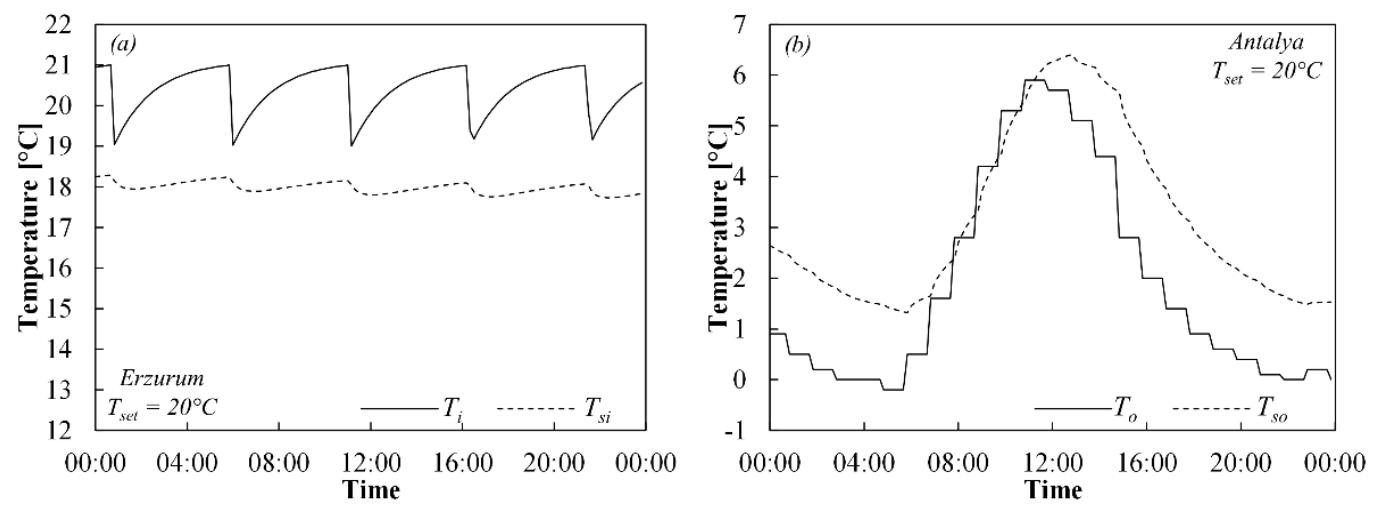

Fig.6. Variation of wall surface temperatures; (a) inner wall surface temperature, (b) outer wall surface temperature 
Fig.7 shows how compressor power $\left(W_{c}\right)$ varies in Bursa on coldest day and it is seen that as the outdoor temperature drops, $W_{c}$ rises due to increase in heating demand. In this study, the calculated $W_{c}$ is below $2 \mathrm{~kW}$ in most cases, as the outdoor temperature rises, $W_{c}$ drops to $1.5 \mathrm{~kW}$ in Bursa even in the coldest day, and this situation is valid for other cities. Kelly and Cocroft [3] found that the $W_{c}$ was around $3 \mathrm{~kW}$ while simulation of Safa et al. [10] indicated that $W_{c}$ barely exceeded $2 \mathrm{~kW}$. Nevertheless, Zhang et al. [18] measured maximum compressor power as $1.21 \mathrm{~kW}$ in coldest province in China, when the outdoor air temperature was below $-10{ }^{\circ} \mathrm{C}$. Compressor power is highly related to heating demand. Therefore, various compressor power may be calculated in regard to different meteorological data and total heat transfer coefficient. Results for $W_{c}$ obtained in this study are acceptable when compared with results calculated or measured by other researchers. More precise AC unit selection can be made by using this model.

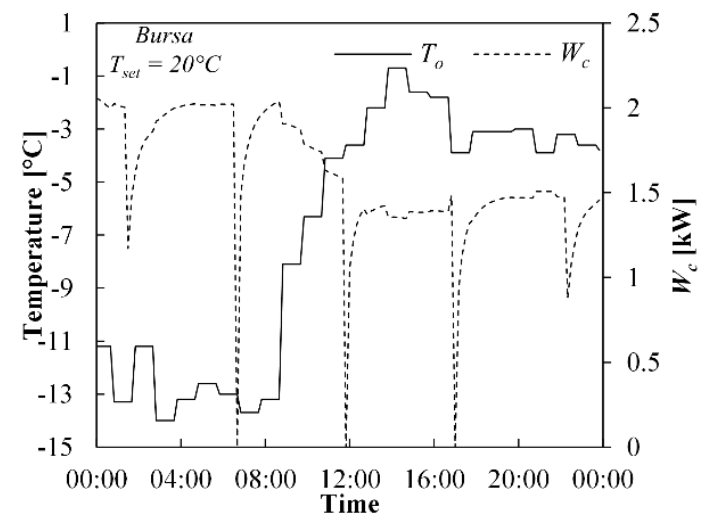

Fig.7. Variation of compressor power in a single day

\section{Conclusion}

Air conditioner or heat pump technology plays a critical role to supply an economic and sustainable way for heating demand of residential buildings in these days that environmental technologies rise in important and energy prices increase. In this study, heating cost of both AC unit and natural gas burner systems was calculated by a dynamical model using four-year meteorological data of three cities with different weather conditions. Transient heat transfer expressions were applied to consider heat storage capacity of wall and window materials in this model and temperature distributions within each layer were calculated by finite difference method. Main conclusions are as follows:

- Annual heating cost is significantly affected by energy prices and weather conditions of the heated building. Natural gas burner applications are more feasible in regions where the climate conditions are stiff while AC usage is more economic in high temperate regions.

- When the coldest day in the meteorological data, used in the model, is considered, it is seen that COP varies between 1.9 and 2.9 and it is concluded that outdoor air temperature has a remarkable influence on COP. The average COP values are found higher in mild climate regions and this affects the heating cost. 
- Inner wall surface temperature $\left(T_{s i}\right)$ changes in parallel with indoor air temperature and the difference, between indoor air temperature and inner wall surface temperature, is below $4{ }^{\circ} \mathrm{C}$.

- Outer wall surface temperature is highly influenced by outdoor air temperature and in some cases $T_{s o}$ may be equal to $T_{o}$. The dissimilar behaviour of surface temperatures can be explained by insulation and the importance of insulation in terms of reducing heat losses and heat cost once again was revealed.

- Various compressor power values may be calculated regarding to different meteorological data and total heat transfer coefficient. Therefore, more precise AC unit selection can be made by using this model.

\section{Acknowledgment}

The author would like to thank Turkish State Meteorological Service for supplying weather data and Emre Çalışkan, Technical Region Manager from Daikin Turkey for assistance with heat pump applications and for comments that greatly improved the manuscript.

\section{Nomenclature}

E - required energy, $[\mathrm{J}]$

$\mathrm{h}-$ heat transfer coefficient, [Wm-2K-1]

$\mathrm{k}$ - heat conduction coefficient, [Wm-1K-1]

$\mathrm{L}$ - Length, [m]

$\mathrm{Nu}-$ Nusselt number $(=\mathrm{hL} / \mathrm{k}),[-]$

Pr - Prandtl number, [-]

Q - heat load, [W]

$\mathrm{q}$ - heat transfer rate per unit area, $[\mathrm{Wm}-2]$;

$\mathrm{Re}-$ Reynolds number, $(=\mathrm{VL} / \mathrm{v}),[-]$

$\mathrm{T}$ - temperature, $\left[{ }^{\circ} \mathrm{C}\right]$

$\mathrm{t}$ - time, [s]

$\mathrm{V}$ - velocity, [ms-1]

$\mathrm{W}-$ power, [W]

$\varepsilon$ - emissivity, [-]

$\sigma-$ Stefan-Boltzmann constant, [Wm-2K-4].

Subscripts

a - air;

$\mathrm{c}$ - compressor;

con - convection;

i - indoor;

o - outdoor;

$\mathrm{r}$ - radiation;

si - indoor surface;

so - outdoor surface;

$\mathrm{t}$ - total;

$\mathrm{w}-$ wind. 


\section{References}

[1] Statistical office of European Union, http://ec.europa.eu/eurostat/statisticsexplained/index.php/Consumption_of_energy\#End-users

[2] Gupta, R., Irving, R., Development and Application of a Domestic Heat Pump Model for Estimating Co2 Emissions Reductions from Domestic Space Heating, Hot Water and Potential Cooling Demand in The Future. Energy and Buildings, 60 (2013), pp. 60-74

[3] Kelly, N. J., Cockroft, J., Analysis of Retrofit Air Source Heat Pump Performance: Results from Detailed Simulations and Comparison to Field Trial Data. Energy and Buildings, 43 (2011), 1, pp. 239-245

[4] Serpen, U., Palabiyık, Y., Economic Analaysis of Residential Building Heating by LPG, Geothermal Heat Pump and Solar Energy, VI. Proc. of UTES'2006, 6th National Clean Energy Symposium, Isparta, Turkey, 2006 (in Turkish language)

[5] Kaya, M., Is1 Costing Analysis Comparison of Heat Pump and Combi Boiler Heating Systems, Electronic Journal of Machine Technologies, 6 (2009), 2, pp. 39-47 (in Turkish language)

[6] Mutlu, M., Çalışkan, E., Investigation of HVAC Systems Usage During Heating Period of a Dwelling Located in Bursa, Proc. of 13th National HVAC Engineering Congress, İzmir, Turkey (2017) (in Turkish language)

[7] Cabrol, L., Rowley, P., Towards Low Carbon Homes - A Simulation Analysis of BuildingIntegrated Air-Source Heat Pump Systems. Energy and Buildings, 48 (2012), pp. 127-136

[8] Pineau, D., et al., Performance Analysis of Heating Systems for Low Energy Houses. Energy and Buildings 65 (2013), pp. 45-54

[9] Zhang, Q., et al., Techno-economic Analysis of Air Source Heat Pump Applied for Space Heating in Northern China. Applied Energy 207 (2017), pp. 533-542

[10] Safa, A. A., et al., Performance of Two-Stage Variable Capacity Air Source Heat Pump: Field Performance Results and TRANSYS Simulation. Energy and Buildings 94 (2015), pp. 80-90

[11] Elsawar, N. et al., Economic Evaluation and Calculations of Energy Savings by Upgrading the Heating Systems in Pre Manufactured Homes. Energy and Buildings 59 (2013), pp. 187-193

[12] Asaee, S. R., et al., Tecno-Economic Feasibility Evaluation of Air to Water Heat Pump Retrofit in the Canadian Housing Stock. Applied Thermal Engineering 111 (2017), pp. 936-949

[13] Gram-Hanssen, K., et al., Air-to-Air Heat Pumps in Real-Life Use: Are Potential Savings Achieved or Are They Transformed into Increased Comfort? Energy and Buildings 53 (2012), pp. 64-79

[14] Çengel, Y. A., Boles, M. A., Thermodynamics: An Engineering Approach, McGraw-Hill, 1994

[15] TSE825, Thermal Insulation Requirements for Buildings, 2008 
[16] Incropera, F. P., DeWitt, D. P., Fundamentals of Heat and Mass Transfer, John Wiley\&Sons, 2006

[17] Madonna, F., Bazzocchi, F., Annual Performance of Reversible Air-to-Water Heat Pumps in Small Residential Buildings. Energy and Buildings 65 (2013), pp. 299-309

[18] Zhang, Y., et al., Application of an Air Source Heat Pump (ASHP) for Heating in Harbin, the Coldest Provincial Capital of China. Energy and Building 138 (2017), pp. 96-103 